\title{
ANALISIS PENERAPAN ALGORITMA NAIVE BAYES UNTUK KLASIFIKASI PRIORITAS PENGEMBANGAN JALAN DI PROVINSI KALIMANTAN SELATAN
}

\author{
Erfan Karyadiputra ${ }^{1)}$, Nadiya Hijriana ${ }^{2)}$ \\ ${ }^{1}$ Fakultas Teknologi Informasi, Universitas Islam Kalimantan Muhammad Arsyad Al Banjari (Erfan \\ Karyadiputra) \\ email : Erfantsy@gmail.com \\ ${ }^{1}$ Fakultas Teknologi Informasi, Universitas Islam Kalimantan Muhammad Arsyad Al Banjari (Nadiya \\ Hijriana) \\ email : Nadyahijriana@gmail.com
}

\begin{abstract}
Abstrak
Provinsi Kalimantan Selatan secara administrasi wilayah terdiri atas 2 kota dan 11 Kabupaten. Pertumbuhan perekonomian di Provinsi Kalimantan Selatan sangat dipengaruhi oleh lancarnya distribusi barang dan jasa. Oleh sebab itu sektor perhubungan terutama infrastruktur jalan memegang peranan sangat penting sebagai prasarana kelancaran suatu distribusi barang dan jasa. Kondisi infrastruktur ruas jalan yang rusak dapat menghambat pendistribusian barang dan jasa sehingga perlu dilakukan perbaikan-perbaikan terhadap jalan tersebut agar distribusi barang dan jasa menjadi lancar. Namun, usaha tersebut terkendala dengan anggaran yang terbatas sehingga instasi terkait harus menentukan daftar prioritas jalan yang akan diperbaiki. Salah satu teknik yang dapat diterapkan yaitu dengan melakukan analisa dengan memanfaatkan teknik data mining berupa penerapan algoritma Naive Bayes Classification untuk mengklasifikasi daftar prioritas pengembangan jalan di Provinsi Kalimantan Selatan. Penerapan algortima naive bayes pada dataset menghasilkan akurasi sebesar $88.27 \%$ dan AUC sebesar 0.933.
\end{abstract}

Keywords : Data Mining, Klasifikasi, Naive Bayes

\section{PENDAHULUAN}

Provinsi Kalimantan Selatan terbentuk pada tahun 1956 berdasarkan UndangUndang No.5 yang secara administrasi wilayahnya terdiri atas 2 kota yaitu Banjarmasin dan Banjarbaru serta 11 kabupaten yaitu Barito Kuala, Tanah Laut, Kotabaru, Banjar, Tapin, Hulu Sungai Selatan, Hulu Sungai Tengah, Hulu Sungai Utara, Tabalong, Tanah Bumbu dan Balangan. Provinsi Kalimantan Selatan memiliki peran penting dalam perekonomian nasional terutama dalam sektor pertanian, perkebunan, peternakan, kehutanan dan perikanan. Provinsi Kalimantan Selatan juga memiliki komuditas utama yaitu kelapa sawit dan karet. Pertumbuhan perekonomian di Provinsi Kalimantan Selatan sangat dipengaruhi oleh lancarnya distribusi barang dan jasa. Oleh sebab itu sektor perhubungan terutama infrastruktur jalan memegang peranan sangat penting sebagai prasarana kelancaran suatu distribusi barang dan jasa. Kondisi infrastruktur ruas jalan yang rusak dapat menghambat pendistribusian barang dan jasa sehingga perlu dilakukan perbaikan-perbaikan terhadap jalan tersebut agar distribusi barang dan jasa menjadi lancar. Namun, usaha tersebut terkendala dengan anggaran yang terbatas sehingga instasi terkait harus menentukan daftar prioritas jalan yang akan diperbaiki. Oleh sebab itu, diperlukan analisa dengan memanfaatkan teknik data mining berupa penerapan algoritma Naive Bayes Classification untuk mengklasifikasi daftar prioritas pengembangan jalan di Provinsi Kalimantan Selatan. 


\section{METODE PENELITIAN}

\section{a. Pengumpulan Data}

Data yang digunakan dalam penelitian ini adalah berasal dari hasil pendataan jalan dan jembatan di Provinsi kalimantan Selatan. Variabel yang akan digunakan pada penelitian ini adalah :

Tabel 1. Variabel Data Jalan Provinsi

\begin{tabular}{|c|c|c|}
\hline Variabel & Keterangan & Kategori \\
\hline $\mathrm{Y}$ & Status & Disetujui, Ditolak \\
\hline $\mathrm{X} 1$ & Klasifikasi Jalan & $\begin{array}{l}\text { Jalan Provinsi, Jalan } \\
\text { Nasional }\end{array}$ \\
\hline $\mathrm{X} 2$ & Jenis Pengerasan & Aspal, Agregat, Tanah \\
\hline $\mathrm{X} 3$ & Kelas Jalan & $\mathrm{K} 1, \mathrm{~K} 2$ \\
\hline $\mathrm{X} 4$ & Kecepatan & - \\
\hline $\mathrm{X} 5$ & Jumlah Lobang & - \\
\hline X6 & Titik Longsor & - \\
\hline $\mathrm{X} 7$ & $\begin{array}{l}\text { Jumlah Longsor } \\
\text { (m) }\end{array}$ & - \\
\hline $\mathrm{X} 8$ & Rusak (Km) & - \\
\hline $\mathrm{X} 9$ & Sedang $(\mathrm{Km})$ & - \\
\hline $\mathrm{X} 10$ & Baik $(\mathrm{Km})$ & - \\
\hline $\mathrm{X} 11$ & Panjang $(\mathrm{Km})$ & - \\
\hline $\mathrm{X} 12$ & Lebar $(\mathrm{m})$ & - \\
\hline $\mathrm{X} 13$ & Tipe Jalan & $\begin{array}{l}2 / 2 \mathrm{D}, 2 / 2 \mathrm{UD}, 4 / 2 \mathrm{D}, 4 / 2 \\
\mathrm{UD}, 2 / 1 \mathrm{D}, 2 / 1 \mathrm{UD}\end{array}$ \\
\hline $\mathrm{X} 14$ & $\begin{array}{l}\text { Alinyemen } \\
\text { Horizontal }\end{array}$ & $\begin{array}{l}\text { Sedikit Tikungan, Lurus, } \\
\text { Banyak Tikungan }\end{array}$ \\
\hline $\mathrm{X} 15$ & $\begin{array}{l}\text { Alinyemen } \\
\text { Vertikal }\end{array}$ & $\begin{array}{l}\text { Bukit, Datar, } \\
\text { Pegunungan }\end{array}$ \\
\hline $\mathrm{X} 16$ & Lalu Lintas & $\begin{array}{l}\text { Sangat Tinggi, Tinggi, } \\
\text { Sedang, Rendah, Sangat } \\
\text { Rendah }\end{array}$ \\
\hline $\mathrm{X} 17$ & Tata Guna Lahan & $\begin{array}{l}\text { Pemukiman, Perkotaan, } \\
\text { Areal Persawahan, } \\
\text { Ruko, Lahan Kosong, } \\
\text { Pertanian, Perkantoran, } \\
\text { Daerah Wisata, } \\
\text { Perkebunan, Tempat } \\
\text { Wisata, Pertambangan }\end{array}$ \\
\hline $\mathrm{X} 18$ & Kondisi & $\begin{array}{l}\text { Baik, Sedang, Rusak, } \\
\text { Rusak Ringan, Rusak } \\
\text { Berat }\end{array}$ \\
\hline
\end{tabular}

\section{b. Pengolahan Data Awal}

Tahapan selanjutnya setelah pengumpulan data maka data tersebut kemudian diolah dengan melakukan preprocessing seperti identifikasi dan inspeksi sejumlah atribut-atribut yang tidak relevan. Kemudian setelah diketahui sejumlah atribut yang tidak relevan maka tahap selanjutnya adalah mengeliminasi sejumlah atribut tersebut dan melakukan subtitusi data sehingga dapat diproses dalam data mining.

\section{c. Eksperimen dan Pengujian Metode}

Terdapat beberapa tahapan dalam melakukan eksperimen, yaitu :
Tahap 1 : Tahap pertama pengujian klasifikasi pertama algoritma naive bayes menggunakan dataset dengan melakukan pergantian beberapa jenis parameter pada $X$ validation yaitu sampling type yang terdiri atas tiga jenis, diantaranya linear sampling, shuffled sampling, dan stratified sampling sehingga didapatkan sampling type yang sesuai untuk digunakan pada data yang diuji

Tahap 2 : Tahap selanjutnya memisahkan dataset menjadi 2 jenis data, yakni data training dan data testing dengan menggunakan pembagian persentase dari jumlah dataset. Apabila data training yang digunakan sebanyak $10 \%$ dari dataset maka persentase data testing adalah $90 \%$. Dan apabila data training yang digunakan sebanyak $20 \%$ dari dataset maka persentase data testing adalah $80 \%$. Jumlah data training apabila dijumlah dengan data testing akan menjadi jumlah dataset tersebut. Jumlah persentase pada data trainning nantinya akan ditentukan berdasarkan perulangan pada proses cross-validation. Contohnya, proses cross-validation pada iterasi ke 4 dari total 10 iterasi, maka persentase jumlah data training adalah $40 \%$ dan persentase jumlah data testing adalah $60 \%$. Proses pemisahan data training dan data testing mengikuti proses $X$-validation dengan jumlah iterasi mulai dari 2,3,4,5,6,7,8,9 dan 10 dan agar data yang digunakan pada proses itu tetap maka akan menggunakan dataset yang sama.

Tahap 3 : Mengevaluasi dan melakukan pengujian performance dengan menggunakan confusion matrix dan Compare ROC sehingga dapat diketahui perbandingan hasil akurasi dan nilai AUC. Nilai AUC digunakan untuk menentukan hasil klasifikasi kedalam klasifikasi sangat baik, klasifikasi baik, klasifikasi cukup, klasifikasi buruk dan klasifikasi salah.

\section{HASIL DAN PEMBAHASAN}

Sebelum melakukan eksperimen dan pengujian model, data-data yang dikumpulkan terlebih dahulu diolah agar dapat diproses dalam data mining. 


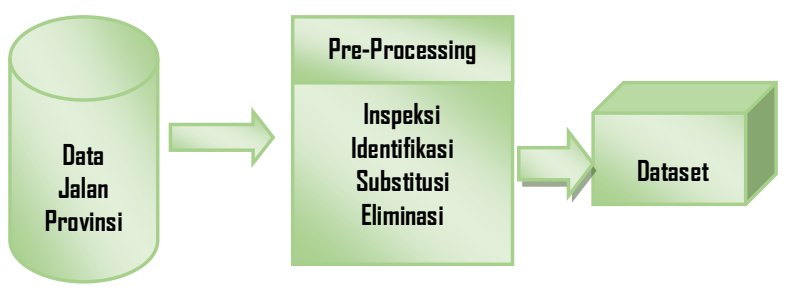

Gambar 1. Pre-Processing

Tahap pertama pengujian klasifikasi pertama algoritma Naive Bayes menggunakan dataset dengan melakukan pergantian beberapa jenis parameter pada $X$ Validation yaitu Sampling Type yang terdiri atas tiga jenis, diantaranya Linear Sampling, Shuffled Sampling, dan Stratified Sampling sehingga didapatkan Sampling Type yang sesuai untuk digunakan pada data yang diuji

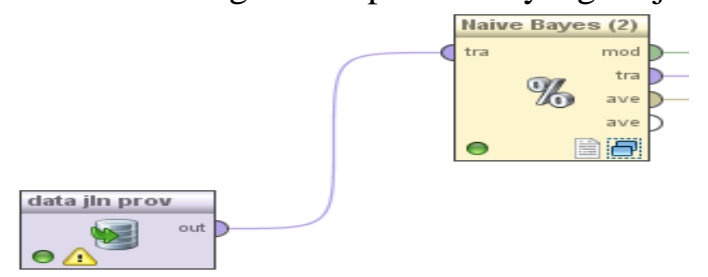

Gambar 2. Pengujian Tipe Sampling

Ketika diimplementasi menghasilkan data sebagai berikut :

Tabel 2. Hasil Pengujian Tipe Sampling

\begin{tabular}{|c|c|c|c|}
\hline $\begin{array}{c}\text { Sampling } \\
\text { Type }\end{array}$ & $\begin{array}{c}\text { Linear } \\
\text { Sampling }\end{array}$ & $\begin{array}{c}\text { Shuffled } \\
\text { Sampling }\end{array}$ & $\begin{array}{c}\text { Stratified } \\
\text { Sampling }\end{array}$ \\
\hline Accuracy & 83.18 & 85.41 & 85.80 \\
\hline
\end{tabular}

Dari pengujian tersebut menghasilkan penggunaan $X$-validation dengan sampling type stratified memiliki tingkat akurasi yang sedikit lebih baik daripada sampling type yang lain. Perbandingan akurasi dari beberapa tipe validasi dalam bentuk grafik seperti gambar dibawah ini

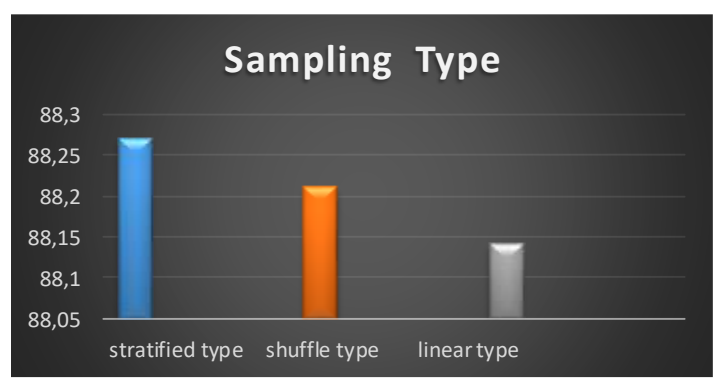

Gambar 2. Pengujian Tipe Sampling
Berdasarkan penelitian dari berbagai percobaan yang ekstensif dan pembuktian teoritis, menunjukkan bahwa penggunaan 10-fold cross-validation adalah pilihan terbaik untuk mendapatkan hasil validasi yang akurat sehingga pada pengujian tersebut didapatkan akurasi 88,27\% dengan nilai AUC sebesar 0,933. Kemudian untuk mendapatkan metode terbaik maka hasil performance Naive Bayes tersebut dibandingkan dengan algoritma lainnya seperti Support Vector Machine (SVM) dan Neural Networks menggunakan Confusion Matrix dan Compare ROC sehingga dapat terlihat perbandingan nilai akurasi dan didapatkan model terbaik terkhusus dalam melakukan klasifikasi daftar prioritas pengembangan jalan provinsi selatan

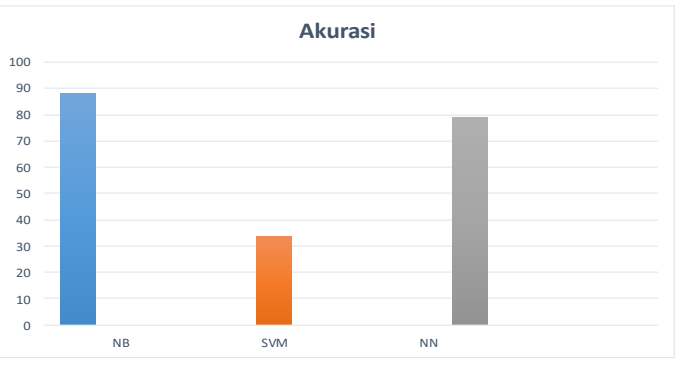

Gambar 3. Hasil Perbandingan Akurasi

Berdasarkan hasil diatas terlihat Naive Bayes lebih baik berdasarkan keunggulan tingkat akurasi sebesar 88,27\% jika dibandingkan dengan algoritma Support Vector Machine (33.65\%) dan Neural Networks (78.97\%).

Pengujian selanjutnya menggunakan Compare ROC. Hasil perbandingan tingkat kehandalan klasifikasi seperti gambar dibawah ini

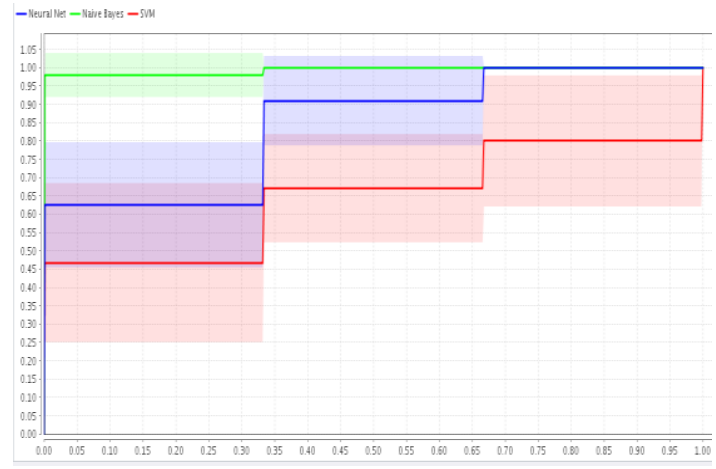

Gambar 4. Hasil Compare ROC 
Dari pengujian tersebut dapat dianalisa bahwa Naive Bayes lebih baik dan termasuk excellent classification berdasarkan keunggulan dalam hal kehandalan dalam klasifikasi dengan nilai sebesar 0,933 karena memiliki nilai AUC yang lebih baik daripada algoritma Support Vector Machine dan Neural Networks.

\section{KESIMPULAN}

Dari hasil penelitian yang dilakukan dari tahap awal pengujian hingga akhir pengujian, dan dari hasil perbandingan dapat disimpulkan bahwa secara umum Naive Bayes lebih baik jika dibandingkan dengan algoritma Support Vector Machine dan Neural Networks berdasarkan keunggulan tingkat akurasi sebagai tingkat kedekatan antara nilai klasifikasi dengan nilai aktual dan berdasarkan keunggulan dalam hal kehandalan dalam klasifikasi karena memiliki nilai AUC yang lebih baik sehingga Naive Bayes dapat diterapkan dalam mengklasifikasi daftar prioritas pengembangan jalan Provinsi Kalimantan Selatan dengan akurasi $88,27 \%$ dan termasuk kedalam excellent classification dengan nilai AUC sebesar 0.930.

\section{REFERENSI}

[1] V. Moertini, Data Mining Sebagai Solusi Bisnis, Integral Vol. 7 No. 1, 2002.

[2] J. Han dan M. Kamber, Data Mining : Concepts and Techniques, Second penyunt., M. R. Jim Gray, Penyunt., San Francisco: Morgan Kaufmann Publishers, 2007.

[3] W. Ian H. dan E. Frank, Data Mining: Practical Machine Learning Tools and Techniques, 2 penyunt., San Francisco: Morgan Kaufmann Publishers is an imprint of Elsevier, 2005.

[4] F. Gorunescu, Data Mining: Concept, Models and Techniques, Romania: Springer, 2010.

[5] Larose, Data Mining Methods And Models, Canada: John Wiley \& Sons,
Inc, 2006.

[6] R. IT, "data mining data preprocessing," 83 2010. [Online]. Available:

https://rencanait.wordpress.com. [Diakses 12 2015].

[7] D. Aprilla, D. A. Baskoro, L. Ambarwati dan I. W. S. Wicaksana, "Belajar Data Mining dengan RapidMiner," Jakarta, academia.edu, 2013.

[8] C. Sammut dan G. Web, Encyclopedia of machine learning, New York: Springer, 2011.

[9] Zhang dan Wang, Application of Bayesian Method to Spam SMS Filtering, International Conference on Information Engineering and Computer Science, 2009.

[10] J. E. Simatupang, Studi Penentuan Prioritas Peningkatan Ruas Jalan Nasional Di Provinsi Kalimantan Selatan, Malang: Brawijaya, 2011.

[11] A. Suwandi, Evaluasi Tingkat Kerusakan Jalan Dengan Metode Pavement Condition Index (PCI) Untuk Menunjang Pengambilan Keputusan, Yogyakarta: UGM, 2011.

[12] Undang-Undang, Undang-Undang Republik Indonesia No 22 Tahun 2009, Jakarta: Dirjen Perhubungan Darat, 2009.

[13] D. PU, Data Jalan \& Jembatan Selama Pelita IV, Departemen Pekerjaan Umum Dirjen Bina Marga, 2011.

[14] J. J. Siang, Jaringan Syaraf Tiruan dan Pemrogramannya Menggunakan Matlab 1st ed, Yogyakarta: Andi Yogyakarta, 2004.

[15] Dong, Y, Xia, Z, Tu dan M. \&. Xing, An Optimization Method For Selecting Parameters In Support Vector Machines, Sixth International Conference On Machine Learning And Applications, 2007. 